\title{
Las relaciones políticas de las empresas exportadoras y su impacto en la gestación de políticas públicas en Chile: el ejemplo de la sociedad Hube y Achelis (1898-1906)*
}

\section{The Political Relations of Exporting Companies and their Impact on the Development of Public Policies in Chile: The Example of Hube and Achelis (1898-1906)}

\author{
Jorge E. Muñoz Sougarret \\ Universidad de Los Lagos, Santiago, Chile, email: jorge.munoz@ulagos.cl
}

\begin{abstract}
Resumen. Esta investigación propone observar las relaciones entabladas por una empresa de capitales extranjeros con los Estados nacionales de Argentina y Chile, preeminentemente con este segundo. Metodológicamente hemos optado por ahondar en las motivaciones que tuvo el mundo político para apoyar a esa empresa, más que detenernos en las exposiciones discursivas de la empresa. Eso nos permitió observar los intereses del mundo político por acercarse a las empresas, colocando a disposición de ellas los bienes estatales a cambio de apoyos acotados y coyunturales.
\end{abstract}

Palabras clave: historia de las empresas; política; nacionalismo.

Abstract. This research proposes to study the relations established by a company of foreign capital with the national states of Argentina and Chile, preeminently with the second. Methodologically, we opted to examine into the motivations of the political world to support this company, rather than stay on the discursive expositions of the company. This allowed us to observe the interest of the political world to benefit the companies, placing at the disposal of them the state assets in exchange for specific supports to his Bills.

Key words: business history; politics; nationalism.

JEL: N86; N96; O24.

Fecha de recepción: 2 de septiembre de 2016. Fecha de aceptación: 13 de diciembre de 2016.

* Este trabajo se enmarca en el Proyecto DIULA NU 12/16 Acceso Restringido: Paisaje, Poder y Política en los Andes Norpatagónicos, financiado por la Dirección de Investigación de la Universidad de Los Lagos. 


\section{INTRODUCCIÓN}

$\mathrm{L}$ a historia de las empresas en América Latina ha comenzado a ser una novedosa área para introducirse a problemáticas propias de la historia política y social. Reflejo de lo anterior es el reciente texto recopilatorio de Fernández y Lluch (2015), donde es claro este entrecruzamiento, al punto que Carlos Dávila (2015, p. 268) afirmó que la manera correcta de estudiar las empresas en América Latina es desde la formación de redes políticas, y no sólo por su búsqueda de eficiencia o competitividad de mercado. Su propuesta interpela a una historiografía que ha optado por otros caminos de análisis.

En Latinoamérica la historia empresarial ha sido reconstruida de manera parcial y, habitualmente, sólo como un factor estadístico que permite medir el grado de avance económico del país. En Chile, la historiografía ha tendido a ensalzar a los empresarios por sus méritos económicos y subvalorarlos en su impacto político y social. Sergio Villalobos en consecutivos textos (1984, p. 26; 1987, pp. 70-71) adujo que los empresarios de fines del siglo XIX únicamente aportaron a la sociedad y política chilena vía la entrega de sus apellidos (por medio de acuerdos matrimoniales con las familias tradicionales) o como financistas de los partidos políticos. ${ }^{1}$

Una mirada diferente tuvo Jean Carrière (1981), quien visualizó la acción política de los empresarios cuando se reunían en gremios, no obstante, aseveró que la mayoría de las agrupaciones empresariales tuvieron más éxito en vetar disposiciones gubernamentales, que en ser propulsoras de proyectos de ley. ${ }^{2}$ Estas conclusiones se llevaron al límite por investigadores que observaron a los empresarios únicamente como un grupo de presión que, con sobornos y apremios, erosionaba el sistema democrático. ${ }^{3}$

En este panorama de atomización empresarial, por un lado, y concentración, por otro, el estudio de Javier Vidal (2015, p. 117) afirmó que era irrelevante tal dicotomía, ya que lo importante era si se contaba con relaciones familiares o de crianza con parlamentarios y agentes gubernamentales. Esta tesis nos lleva a preguntarnos si no existieron otros factores que explicarían el apoyo político a una empresa o empresario, como po-

${ }^{1}$ Con variaciones pequeñas, esta tesis ha sido reproducida por subsecuentes investigadores, véanse Bauer (1990, pp. 246-250), Cavieres (2002, p. 156), Correa (2011), Harris (1998), Mazzei (1998), Moulian y Torres (2011), Nazer (2000, p. 70), Ortega (1999, p. 69) y Pinto (2002, p. 65).

${ }^{2}$ Otros investigadores argentinos y chilenos de las agrupaciones gremiales empresariales han coincidido con el análisis de Carrière, véanse Álvarez (2015), Brennan y Rougier (2013), Carreño (2008), Hora $(2009,2015)$ y Simonassi (2015).

${ }^{3}$ En Chile la tesis de la oligarquía oculta fue establecida por el historiador conservador Gonzalo Vial (1981-2001, 2003), replicada en versiones moderadas (Gazmuri, 1980; Góngora, 2003, pp. 115-118; Jocelyn-Holt, 1997, p. 51; Ortega, 1984) como más radicales (Salazar, 2015, pp. 403 y 484). 
drían ser la nacionalidad, ideología política o posición geopolítica del emprendimiento. Eso nos impulsó a buscar el ejemplo de una empresa que careciendo de lazos familiares y de círculos sociales con el mundo político de Chile, se vio beneficiada con importantes apoyos.

En vista de la dificultad para poder reconstruir acuerdos y negociaciones verbales entre los empresarios y políticos, hemos optado por abocarnos a rescatar desde los discursos parlamentarios, decretos e informes gubernamentales y prensa en general, aquellos elementos que pudieran develar la existencia de un trato preferencial. Consideramos que estas fuentes han sido subutilizadas por la historia de las empresas, que ha preferido los textos escritos por empresarios (al momento de definir su mirada política). En nuestro trabajo intentaremos utilizar tanto los textos provenientes del mundo político como empresarial, esperando encontrar concordancias y motivaciones empresariales en los cuerpos legales.

Los factores previamente expuestos nos impulsaron a seleccionar una empresa comercial de capitales alemanes que se instaló en los valles andinos que disputaban Argentina y Chile, a fines del siglo XIX. Esta en apariencia, careciendo de todos los elementos presentados por la historiografía -no tuvo relaciones familiares o sociales con el mundo político, no financió directamente campañas políticas y no participó en ninguna agrupación empresarial-, fue beneficiada con subsidios y prerrogativas a escala binacional.

\section{La sociedad Hube y Achelis y el mercado lanar en el Cono Sur americano}

La influencia de la producción salitrera en el erario chileno, a fines del siglo XIX, hace que se obvie el crecimiento del mercado lanar en las provincias del sur del país. La exportación de lana por Argentina y Chile hacia los mercados británicos y alemanes creció debido a la competencia comercial que estaban ejecutando ambos países europeos (Merrett y Ville, 2015). Alemania, que buscaba posesionarse como el principal receptor de lana americana, recelaba que los dos mayores puertos de exportación lanar del Cono Sur americano (Punta Arenas, en Chile, y Buenos Aires, en Argentina) estuvieran bajo el control tácito de empresas de capitales británicos, por lo que buscó posicionarse en puertos menores, donde fueran empresas de capitales germanos las principales controladoras (Merrett y Ville, 2015, pp. 239 y 246; Sabato, 1983, p. 80). Apareciendo la figura de Puerto Montt, en la provincia chilena de Llanquihue, como un espacio de amplias potencialidades para transformarse en un puerto de exportación de la lana proveniente de la Patagonia argentina. 
A inicios del siglo xx, Puerto Montt era el penúltimo puerto de importancia en Chile -en 1902, el mejor año en el periodo abarcado por este estudio, significó $0.08 \%$ de las exportaciones y $0.13 \%$ de las importaciones nacionales (El comercio esterior, 1903, pp. 286 y 293)-, pero contaba con dos potencialidades significativas, a ojos alemanes: en la ciudad y provincia se encontraba una importante comunidad de inmigrantes germanos, con un pujante grupo empresarial y, aunque la producción provincial de lana era mínima, la existencia de una cordillera andina baja facilitaba el tráfico entre la Patagonia y el océano Pacífico.

A diferencia de lo acaecido en Tierra del Fuego, a fines del siglo XIX no había podido establecerse un mercado lanar en la Patagonia norte debido a las disputas de límites entre Argentina y Chile. En las últimas décadas del siglo XIX ambos países se habían propuesto solucionar sus diferencias de fronteras por vía diplomática (pero siempre con la espada de la guerra sobre sus cabezas), siendo el punto más conflictivo entre los paralelos 40 y 45 de latitud sur, donde se concentraban fértiles valles andinos con capacidad para sostener ganado y personas en gran número (Lacoste, 2003). Los Estados pactaron someter la soberanía de tales valles a un arbitraje internacional (asumido por la corona británica, con veedores alemanes e italianos); sin embargo, los Estados contravinieron el acuerdo al invertir en la instalación de población u obras públicas que demostraran soberanía en los valles andinos. De esa manera, discursivamente, los valles andinos pasaron a considerarse simbólicos para el ethos nacional, emergiendo, como el más icónico de estos, la cuenca del lago Nahuel Huapi (Moreno, 1898, p. 460).

Pero el lago Nahuel Huapi no solamente tenía importancia simbólica, sino que se encontraba situado en una concatenación de lagos (Llanquihue, Todos los Santos, Frío y Nahuel Huapi) que permitían remontar fácilmente la cordillera casi en cualquier temporada. Además, su cercanía con Puerto Montt situaba a Nahuel Huapi como una potencial puerta de salida de las materias primas de la meseta central patagónica. Tales factores fueron observados por inversores alemanes que buscaron situarse en la región para poder construir una ruta de exportación de lana cruda.

En consideración de tales antecedentes, arribó a Puerto Montt, en 1899, Friedrich Adolph Achelis, hijo de una importante familia de Bremen y fundadora de la naviera Roland. En la ciudad se asoció con un empresario local, también de origen alemán, Federico Hube, quien ya comerciaba con los productores de Nahuel Huapi. A primeras luces, de esta alianza surgen varios factores destacables, como la selección de Puerto Montt como lugar de asentamiento de Achelis. La familia Achelis era accionista de una naviera que, en conjunto con la también germana Kosmos, controlaba cerca de un cuarto de todo el cabotaje chileno y, por lo tanto, habría 
sido esperable que se asentaran en el puerto principal del país, Valparaíso (Couyoumdjian, 1986, p. 42). Por medio de la biografía familiar (Rabelli \& Sille editores, 1921, pp. 77-78) sabemos que se hicieron estudios en todos los pasos entre Argentina y Chile, decidiéndose por los situados en el paralelo 40 por sus facilidades anuales de tránsito. Además, investigaciones recientes (Overlack, 1998; Rinke, 2014) han mostrado que las navieras (que estaban fuertemente subvencionadas por la armada alemana, y, por lo mismo, alineadas a su lectura imperial) recelaban de la influencia de las empresas comerciales inglesas en los principales puertos del Cono Sur americano, situación que no se daba en Puerto Montt.

La conexión con Alemania de la nueva sociedad empresarial Hube y Achelis se transformó en una herramienta de negociación con los Estados nacionales. Ya que pudo penetrar los círculos políticos de decisión desde las estructuras diplomáticas y, una vez ahí, presionar a los gobiernos para que dictaran normas preferenciales para sus giros -usando el argumento amedrentador del quiebre de relaciones económicas y diplomáticas, situación replicada en otros casos como mostró Andrés Regalsky (1996, p. 194) con los empresarios franceses de los ferrocarriles en Argentina.

Para comprender nuestro caso, que contiene diversas aristas, nos hemos propuesto no separarnos del decurso de la empresa Hube y Achelis, $\mathrm{y}$, desde ella, tratar de exponer el entrecruzamiento de motivaciones que marcaron sus relaciones con el mundo político. En definitiva, hemos dividido la exposición en tres secciones: una primera, que podríamos situar entre los años 1898 y 1902, se centrará en el establecimiento de lazos políticos coyunturales con actores gubernamentales e integrantes de las comisiones de límites de Argentina y Chile; una segunda, entre los años 1903 y 1904, puede considerarse como una maduración política de la empresa y sus conexiones, que han avanzado desde situaciones coyunturales a un reconocimiento a nivel nacional, además de una valoración nacionalista de sus acciones y discursos, y, tercera, entre los años 1905 y 1906, vemos la consolidación política de la empresa, al imponer su mirada comercial sobre las barreras que quisieron implementar los Estados argentino y chileno.

\section{RELIGIÓN, PODER LOCAL Y LA IDEA DE PROGRESO EN LA PROVINCIA DE LLANQUIHUE}

Uno de los eventos más significativos en la provincia de Llanquihue, en la década final del siglo XIX, fue la politización de los conflictos entre las comunidades de protestantes y católicos. Desde mediados del siglo XIX se produjo una importante migración de población germana a la provincia de Valdivia, en Chile, al punto que se creó una organización adminis- 
trativa nueva únicamente para contenerlos -la provincia de Llanquihue, siendo su capital Puerto Montt (Weil, 2006, p. 63). Es ampliamente reconocido por la historiografía que gran parte de estos colonos eran de religión luterana y de tendencias políticas liberales (Krebs, 2001), cabe mencionar que con posterioridad, en la década de 1870 , se produjo la emigración de germanos católicos a la provincia, probablemente impulsados por el acoso que sufría tal comunidad luego de la unificación (Bernedo, 1993). Contrariando a este crucial antecedente, las comunidades de germanos de la provincia convivieron en tensa calma hasta que aquellas diferencias fueron utilizadas políticamente por los partidos radical y conservador, con posterioridad a la guerra civil de 1891 .

La guerra civil de 1891 quebró la tradición presidencialista de Chile, gestándose una serie de alianzas de partidos para hacerse como la principal fuerza política. Así aparecieron dos facciones, una católica (conformado por los partidos conservador y liberal-democrático) y otra anticlerical (partido radical); los acompañaba el partido liberal que, de manera pendular, se movía entre ambas -empero todos los partidos eran pro mercado y libre empresa- (Correa, 1981, p. 85). Esta lucha partidaria adquirió consonancias religiosas en la provincia de Llanquihue, dividiendo a la comunidad de germanos y provocando abiertas luchas entre las facciones, llegando a enfrentamientos públicos, quema de iglesias y asesinatos (Blancpain, 1970).

En relación con lo anterior, las empresas locales también pasaron a ser vistas según un prisma político y religioso, por lo que los gobiernos posteriores a la guerra civil (conducidos por el partido liberal, con apoyo de conservadores y liberales-democráticos) rara vez apoyaron a los empresarios germanos de la provincia, mayoritariamente luteranos y adherentes al partido radical. Por ejemplo, desde mediados de la década de 1890 la familia Wiederhold (proveniente de Osorno, luterana y radical) había iniciado la instalación de tiendas comerciales en los márgenes del lago Nahuel Huapi para captar los productos locales y exportarlos por Chile; sin embargo, no fue hasta que ella se asoció y entregó la dirección de sus tiendas a Federico Hube, germano católico asentado en Puerto Montt, que se gestaron los primeros apoyos políticos al intercambio cordillerano (Steffen, 1910, p. 223).

A fines del siglo XIX, Federico Hube era un reconocido empresario de Puerto Montt, tanto por sus acciones individuales como por la conexión matrimonial con una importante familia de comerciantes de la ciudad (Fábregas, 2014, p. 356). La comunión de ambos elementos, junto con su ejercicio del catolicismo, lo arrimaron a los representantes gubernamentales y parlamentarios conservadores, liberales y liberal-democráticos. Tales afinidades habrían acercado a Hube al senador por la provincia, el 
conservador Ramón Rozas, quien asumió la vocería de la empresa frente al parlamento chileno.

Rozas, que había sido electo por la circunscripción de Llanquihue en 1897, centró su actuación local en la defensa de los católicos de la provincia. En muchos sentidos, Rozas fue un signo de la transición que vivió el partido conservador, entre sus convenciones de 1891 y 1895, donde abandonaron los recelos hacia el liberalismo-protestantismo en pos de abocarse a frenar el nacimiento del socialismo y la cuestión social (Corvalán, 2002, pp. 56-57; Muñoz, 2009, p. 44). La aparición de la cuestión social como una problemática política hizo que el partido buscara un acercamiento más evidente con los sectores industriales y comerciales, sin perder, por este giro, sus antiguas adhesiones. De esta manera, Rozas optó por intentar fusionar la mirada tradicional del partido con su nuevo apoyo empresarial, especialmente cuando sus ataques a la comunidad germana de Llanquihue le habían significado la imputación de su elección en 1900 (Ramón, 2003, t. IV, p. 81). Tal aggiornamiento de Rozas lo llevó a buscar un empresario provincial que teniendo importancia económica y social dentro de la comunidad germana, fuera católico. Encajando la figura de Hube (y su empresa) perfectamente en ese patrón.

Desde 1899 Rozas impulsó en el Senado una serie de subsidios para la empresa de Hube y Achelis, siendo el más importante la erogación pública de las mejoras viales del paso Pérez Rosales, junto con solicitar la rápida construcción de un ferrocarril que uniera Puerto Montt con el resto del país, aduciendo que "afluye también a Puerto Montt el tráfico trasandino del boquete Pérez Rosales, creciente de año en año i ya de cientos de miles de pesos" (Rozas, 1899, p. 123). ${ }^{4}$ Igualmente, el senador Rozas consideró que apoyar con inversiones viales a la empresa podría beneficiar a Chile en su disputa de límites con Argentina, por lo que pidió, privadamente, que la intendencia de Llanquihue hiciera una evaluación del costo que tendría un camino entre el paso Pérez Rosales y el lago Nahuel Huapi. ${ }^{5}$

${ }^{4}$ En una alocución en el Senado, Rozas habló así de la empresa y los beneficios que la misma reportaba para el desarrollo provincial y nacional: "Existe pendiente en el Ministerio de Industria i Obras Públicas una reclamación de la respetable casa comercial de los señores Hube i $\mathrm{C}^{\mathrm{a}}$., establecida en la ciudad de Puerto Montt, sobre la construcción de un camino, desde esa ciudad a la República Argentina Nahuelhuapi, o sea el de Ensenada al boquete Pérez Rosales, cuyos antecedentes deseo examinar prolijamente para ver de modo de impulsar de nuevo los trabajos de ese camino hasta tanto quede sólidamente expedito para el servicio público, con evidente provecho para la provincia de Llanquihue i para todo el país." Véase Diario de sesiones, Cámara de Senadores, Sesión 30a. ordinaria, 26 de diciembre de 1899, p. 853. Agradecemos al investigador local de Puerto Montt, Rudy Carrasco, por informarnos sobre este discurso del senador Rozas.

${ }^{5}$ Telegrama enviado a Ramón Rozas, Puerto Montt, 4 de diciembre de 1900. Intendencia de Llanquihue, Copiador telegramas despachados en los años 1899, 1900 y 1901, fs. s. n. Archivo Liceo de Hombres de Puerto Montt, Puerto Montt, Chile. 
Las alocuciones públicas de Rozas fueron la primera presentación, a nivel nacional, de la Hube y Achelis y, en muchos sentidos, consolidó su imagen como una empresa que no sólo aportaba al progreso de Llanquihue, ${ }^{6}$ sino que, además, defendía la soberanía chilena en los Andes. Esta última tesis fue profundizada por el diputado liberal-democrático por Osorno, Efraín Vásquez, quien en 1902 afirmó que debía apoyarse a las empresas privadas que ejercían soberanía nacional en las regiones disputadas, tal como la Hube y Achelis. ${ }^{7}$

En Argentina la "nacionalidad" de la Hube y Achelis no había pasado desapercibida, lo que dio origen a una investigación por contrabando hacia ella por parte del gobierno territorial, junto con importantes notas de prensa que cuestionaban su posición aventajada en Nahuel Huapi. ${ }^{8}$ Podemos suponer que este acoso allanó el camino para que la Hube y Achelis negociara su afiliación nacional con Argentina, frente a la inminente visita de la comisión inglesa de límites. Así, en abril de 1902, la Hube y Achelis arrendó sus servicios e inmuebles a Argentina, al punto de usar exclusiva-

${ }^{6} \mathrm{Si}$ nos abocamos a aspectos puramente económicos, y utilizando como base el recuento contable de la aduana argentina en Nahuel Huapi, citado por Méndez (2010, p. 119), a inicios del siglo Xx la empresa exportó en lana sucia, aproximadamente, 500 toneladas anuales, por un valor neto de 22900 libras esterlinas (a precio de Buenos Aires), equivalente a 146560 pesos chilenos. Cual dato de contexto podemos decir que en 1902 el monto total de las exportaciones en Puerto Montt ascendió a 147902 pesos, lo que nos permite observar la significativa importancia de la empresa para la provincia. Para calcular el tipo de cambio hemos usado la tabla presentada en Mario Matus (2012, p. 34); los precios de la lana sin lavar en el mercado europeo se extrajeron de Ernesto Torquist y Compañía Limitada (1919, pp. IV y 74) y la estadística comercial de Puerto Montt provino de El comercio esterior, 1903, p. 293).

${ }^{7}$ A continuación, presentaremos un fragmento de la presentación de Efraín Vásquez: "Este ferrocarril será estratégico, porque permitiría la defensa del país que podría ser fácilmente invadido por la cordillera; i a la vez hará viable la colonización de toda aquella vasta región que se halla aún sin ser explotada. Los vapores de Europa tocarán primeramente en Puerto Montt y entonces la correspondencia adelantará dos o tres días a lo que hoy se demora en llegar a Santiago. [...] Del propio modo acercará el comercio con la Argentina, cuyo ferrocarril a Nahuelhuapi quedará muy poco distante de él, ya que, gracias a los esfuerzos de la casa de comercio de don Federico Hube, de Puerto Montt, se halla establecida la navegación de los lagos Todos (los) Santos y Nahuelhuapi, a donde, sin auxilio oficial, por iniciativa propia y venciendo mil inconvenientes, dicho comerciante trasladó las piezas de sus vapores, a lomo de mula, para armarlos en las propias riberas de esos lagos.” Diario de Sesiones, Cámara de Diputados, Sesión 11a. ordinaria, 19 de junio de 1902, p. 248.

8 "Una mirada al mapa enseña que Puerto Montt aspira a constituirse en la Punta Arenas del Neuquén, es decir en el emporio chileno, vía de la exportación de otro Santa Cruz y de otra Tierra del Fuego argentinas, antes del establecimiento regular de la navegación del sud. Hoy mismo, en el lago Nahuel Huapi existe una flotilla de vapores mercantes, de empresa chilena, á cargo del señor Hübe [sic], ejemplar típico de esa curiosa población alemana diseminada en el extremo de aquel país. En un número anterior hemos presentado estos barcos que se estivan de lana, maderas, etc. siguiendo viaje por tierra la mercadería en pequeñas carretas, denominadas catanga, hasta dar con el puerto de salida." Véase La cuestión internacional. Caminos chilenos que la han motivado (1901). Caras y Caretas, 167, p. s. n. 
mente su bandera. ${ }^{9}$ Un hecho que fue destacado por el árbitro inglés, y, según él, habría reafirmado su visión de que era Argentina quien ejercía soberanía en los lagos Frío y Nahuel Huapi (Holdich, 1904, pp. 278, 291 y 296). Con posterioridad al fallo arbitral, que entregó las cuencas de Nahuel Huapi y de El Manso a Argentina, se premió políticamente la actitud de la Hube y Achelis, acallándose las investigaciones iniciadas en su contra y las voces críticas de la prensa bonaerense sobre el papel de la empresa en la región. ${ }^{10} \mathrm{Y}$ este apoyo continuó profundizándose, al punto de permitir la compra y concesión de tierras en Río Negro y Neuquén, como veremos más adelante.

Resumiendo, en los primeros años de la Hube y Achelis podemos notar cómo la empresa supo granjearse apoyos puntuales con representantes políticos locales para, con posterioridad, profundizar tales lazos con los gobiernos nacionales al amparo del nacionalismo que preñó las discusiones entre Argentina y Chile. Ahí vimos cómo la empresa, de manera plástica, se acomodó a los discursos nacionalistas y pasó a ser considerada, por parte de los Estados, como una herramienta de ejercicio de soberanía. Esa nueva posición la llevará a escalar a nuevas posiciones de influencia política.

\section{NACIONALISMO EMPRESARIAL O LAS DISPUTAS POR LA SOBERANÍA ECONÓMICA DE LOS VALLES ANDINOS}

Durante esta segunda sección nos encontramos con una profundización de las redes políticas de la Hube y Achelis, ascendiendo desde las representa-

\footnotetext{
${ }^{9}$ El documento más claro en este sentido es el telegrama enviado por el perito Moreno a su ayudante Emilio Frey, donde a pocos días de arribar la comisión arbitral inglesa le solicitaba lo siguiente: "Espero llegar el seis procuraré que el vapor de Hube queda [sic] a nuestra disposición desde el siete pues quiero ir inmediatamente a Puerto Blest para encontrarme con el coronel Holdich, insista en esto pues temo que los chilenos contraten el vapor. Voy por el camino de los carros al oriente del río -Suyo Fco. P. Moreno. Neuquén." Véase Moreno a Emilio Frey (31 de marzo de 1902). Telegrama 251, documento 6, Comisión de Límites. Colección Frey, bibliorato núm. 2. Museo de la Patagonia, Bariloche, Argentina.

${ }^{10}$ En tanto, un corresponsal del diario La Nación, que acompañó a la Comisión Inglesa, claramente no creyó en la tesis de una Hube y Achelis argentina: "La casa no tiene comercio determinado, hace todo lo que cree que puede producirle ganancias: así, pues, es tienda, mercería, ferretería, almacén, corralón de materiales de construcción, barraca de frutos del país, carnicería, molino, aserradero, charquería, fonda y posada y agencia de transportes. Como ya lo he dicho, la casa matriz está establecida en Chile, en Puerto Montt, lo que vale decir que las transacciones siguen principalmente esta vía y no la argentina [...] Estos alemanes, se dice, son agentes chilenos, contrabandean mercancías, explotan los bosques sin permiso, sacrifican al trabajador, y un cúmulo de cosas tan graves como estas, de que no quiero hacerme eco, porque no he venido a relatar charlas, sino para observar é investigar la verdad, de la que doy cuenta en forma más o menos desaliñada", citado por Fiori y Veras (2002, pp. 87-88).
} 
ciones políticas a nivel local a organismos y personas con figuración nacional. Un ejemplo lo podemos ver en la defensa parlamentaria que se hizo en pos de renovar un subsidio entregado a la Hube y Achelis (por traslado de correspondencia entre Chile a Argentina), donde emergen elementos de tradición e innovación dentro de sus relaciones con el mundo político.

En abril de 1902 la intendencia de Llanquihue entregó a la Hube y Achelis la concesión del remozado paso Pérez Rosales, cuyos arreglos se habían producido por la visita del árbitro inglés. Con tal entrega esperó el Estado chileno obtener el apoyo irrestricto de la Hube y Achelis durante el litigio con Argentina, lo cual no ocurrió. ${ }^{11} \mathrm{Y}$, sorpresivamente, la empresa pareció no sufrir de una condena directa por el Estado chileno, ${ }^{12}$ ya que en octubre de ese año el senador Rozas solicitó en el Senado que se repusiera el contrato gubernamental que cancelaba una cuota fija anual a la Hube y Achelis por el traslado de correspondencia entre Argentina y Chile. El ministro del Interior, Ramón Barros Luco, afirmó que conocía a la empresa y valoraba que gracias a su mediación "se ha despachado toda la correspondencia dirigida por la Comisión de Límites a la Comisión Arbitral Inglesa", sin embargo, debía ser una comisión mixta la que debía aprobar la renovación del contrato. ${ }^{13}$ En jornadas posteriores se produjo la importante intervención del senador liberal por Valparaíso, Manuel Ossa, que forzó al ministro a aprobar la renovación del contrato y, al año siguiente, decidir que el mismo se renovaría automáticamente sin pasar por la discusión de la ley de presupuesto. ${ }^{14}$

La efectiva intervención de Ossa para lograr la renovación del contrato, nos remite a una relación política distinta a la entablada entre la Hube y Achelis y los parlamentarios de la circunscripción de la Llanquihue. En el ámbito privado el senador Ossa era un prestigioso empresario de la

${ }^{11}$ Acta de entrega definitiva (12 de abril de 1902). Intendencia de Llanquihue, Recibidos del ingeniero de la provincia los años 1900 a 1904, núm. 33, f. s. n. Archivo Liceo de Hombres de Puerto Montt, Puerto Montt, Chile.

${ }^{12}$ Es complejo especular sobre este tema pero, a la luz de la información actual, podemos proponer una respuesta. Todos los informes de época, citados por Donoso (1936, p. 10), remiten a la figura del geógrafo alemán Hans Steffen como el encargado de la logística del traslado de la comisión inglesa desde Chile a Argentina. Él, en sus informes presentados al ejecutivo y posteriormente publicados, siempre se refirió de forma neutra a la Hube y Achelis, obviando el uso de la bandera argentina que tanto resaltó el árbitro Holdich (Steffen, 2010, t. II, pp. 387-388). Probablemente, y siguiendo el telegrama de Moreno (31 de marzo de 1902), ocurrió que Steffen no pudo contratar a la Hube y Achelis y optó por no mencionar aquello en sus informes oficiales. En conclusión, en vista que el informe de Steffen era inocuo y la memoria de Holdich no se publicó hasta 1904, el ejecutivo chileno no tuvo argumentos para restarle apoyo a la empresa durante los años posteriores a la visita de la comisión inglesa.

${ }^{13}$ Diario de Sesiones, Cámara de Senadores, Sesión 5a. extraordinaria, 24 de octubre de 1902, p. 101.

${ }_{14}$ Diario de Sesiones, Cámara de Senadores, Sesión 8a. extraordinaria, 28 de octubre de 1902, p. 161; Sesión 13a. extraordinaria, 7 de noviembre de 1903, pp. 299-300. 
minería y constructor de vías férreas, y a fines de la década de 1890 ganó la concesión para construir el ferrocarril que unió Pichirropulli (provincia de Valdivia) con Osorno (Camus, 1997). Eso hizo que conociera de primera mano las potencialidades de la interconexión entre la ruta esteoeste del tráfico de la Hube y Achelis con el eje vertical (norte-sur) de los ferrocarriles. ${ }^{15}$ Tan importante como este conocimiento previo fue que, en 1903, el senador Ossa estaba postulando para obtener la concesión de la construcción del ferrocarril entre Osorno y Puerto Montt, momento en el que, siguiendo lo investigado por Carrasco (2015, pp. 68-72), él organizó un fuerte lobby dentro del Senado para que se lograra su designación. Aun cuando no fue aceptada su propuesta, se produjeron presentaciones para promover los parabienes del ferrocarril para una provincia en crecimiento, como se caracterizaba a Llanquihue, y en muchas de ellas se aseveró que un pilar fundamental de la provincia era la Hube y Achelis. ${ }^{16}$

El mutuo conocimiento entre la Hube y Achelis y el senador Ossa puede remitirnos a acuerdos estratégicos que responderían a la construcción de obras públicas que facilitaban el movimiento de los productos de ciertas empresas, que, a cambio, prodigaban apoyos locales, tanto a nivel pecuniario como eleccionario - vía la cooptación del ejercicio de votación de trabajadores, empleados y proveedores. ${ }^{17}$

La ampliación de las redes políticas de la Hube y Achelis en Chile se correspondía con la consolidación de las ya formadas por la empresa en Argentina. Con posterioridad a que el laudo arbitral entregó toda la cuenca del Nahuel Huapi a Argentina, el gobierno creó la colonia pastoril de Nahuel Huapi en 1902, reservándose 400 hectáreas para la fundación de la ciudad de San Carlos, de las que 150 fueron vendidas a la Hube y Achelis (Matossian, 2012, p. 73). Aquello coincidió con la publicación de las memorias de los integrantes de la comisión de límites, en muchas de

${ }^{15}$ En 1903 se recordó la intervención del año anterior del senador Ossa, ella grafica extensamente lo ya expuesto: "Este es un hecho que conozco personalmente, i del que puedo hablar con entero conocimiento de causa. Al treinta o cuarenta por ciento entre Puerto Montt i Nahuelhuapi se debe el movimiento argentino que se acentúa día a día. Hoy se puede hacer en diecisiete horas el viaje desde Puerto Montt a Nahuelhuapi, cruzando el vapor por tres lagos sucesivos; i acortando así las distancias, el comercio se ha triplicado en estos últimos tiempos. I no es este el único servicio que puede prestar la Casa de Hube, pues, según se me ha informado, tiene el propósito de tender una vía férrea entre Nahuelhuapi i el seno del Reloncaví, trayecto que se recorrería en dieciocho horas. Por otra parte, veo que para la navegación del río Imperial, para la del lago Llanquihue i otras, se dan subvenciones cuantiosas. Bien podrían, pues, consultarse los cuatro mil ochocientos pesos que ahora se piden, tanto más cuanto que no es sino la renovación de un contrato i una medida verdaderamente ventajosa, económica y previsora." Véase Diario de Sesiones, Cámara de Senadores, Sesión 13a. extraordinaria, 7 de noviembre de 1903, pp. 289-290.

${ }^{16}$ Véase Diario de Sesiones, Cámara de Senadores, Sesión 49a. extraordinaria, 31 de diciembre de 1903, p. 999.

${ }_{17}$ Para un estudio de prácticas similares y contemporáneas en las Américas, véase Ross y Karcher (2012, pp. 18-19). 
ellas aparecía nombrada la empresa y, en no pocas, la imagen presentada era claramente laudatoria. ${ }^{18}$ La empresa buscó favorecerse con ello al solicitar al gobierno del presidente argentino Julio Roca la exención de pago de aduanas en Nahuel Huapi. Una petición de la empresa desde $1901 .{ }^{19}$

El gobierno de Roca se caracterizó por realizar acuerdos políticos con las empresas privadas situadas en los territorios nacionales (Béjar, 2005, pp. 22-23), y, en este caso, no fue diferente al dictarse la eliminación de aduana a los productos internados desde el océano Pacífico hacia el territorio de Río Negro. ${ }^{20}$ Gracias a esta disposición la empresa pudo importar desde Europa a Nahuel Huapi, vía Puerto Montt, sin pagar costos de inter-

${ }^{18}$ Por ejemplo, Clemente Onelli (2007) recordará en sus memorias que en 1903: "Visitamos Puerto Moreno y llegamos al fin a San Carlos de Nahuel Huapi, donde la casa Hube y Achelis y el señor Luis Horn han iniciado la civilización de ese lago poco conocido, con chalets, molinos, casas, caminos, muelles, el vapor mismo en que navego, y todo eso a pesar de los tropiezos inherentes al desierto y que aumentan los malévolos informes de los haraganes de la comarca, que comunicaban y comunican aún al gobierno el inmenso daño que hacen esos esforzados ocupando algunas hectáreas de tierra con sus huertas y edificios. El general Roca, que con las armas afirmó la soberanía sobre ese lago y que tiene un verdadero culto por esa joya andina, es lástima que en sus giras presidenciales al sur no haya vuelto a esos parajes divinos, para facilitar con su influencia la obra civilizadora y enérgica de esos valientes que han empleado allí importantes capitales" (p. 32).

${ }^{19}$ En 1901, Federico Hube escribió al embajador argentino en Chile, rechazando el acoso gubernamental contra su empresa y destacando su valor para la economía del lago: "Que [la] fuerza de línea acantonada en San Martín de los Andes, por orden del Señor Ministro del ramo o de esa gobernación, para vigilar los boquetes de la Cordillera, estorban el libre tráfico de las mercaderías procedentes de este país por vía Pérez Rosales para Nahuel Huapi. Nada tendría que observar a la medida sobre vigilancia, ni de los boquetes y de todas las operaciones de la casa Hube \& Achelis en su sucursal de Nahuel Huapi, siempre que se procediera equitativamente y sin ánimo de hostilidad para la expresada casa, que es de sobra conocida de los agentes de esa Gobernación o del Gobierno Central, por cuanto permanecen hospedados en dicha casa todo el tiempo que dura la comisión que se les ha confiado. De tal suerte que las negociaciones de la Casa Hube y Achelis se llevan a cabo con toda limpieza y a vista y presencia de los agentes fiscales, sin que jamás se haya comprobado la más ligera irregularidad, a pesar de las reclamaciones antojadizas de algunos comerciantes, que se sienten heridos en sus intereses por una imaginaria rivalidad. [...] La casa de Hube \& Achelis, y este el punto principal sobre el que quiero llamar la atención no es un negocio de tres al cuarto que pueda mirarse con ánimo ligero y de menosprecio. Su capital social, el desarrollo de sus negocios, la seriedad y solvencia de sus socios, y las ingentes sumas gastadas en edificios, caminos, vapores -en este solo ramo se han invertido más de 385000 pesos-, la hacen acreedora al respeto y consideración que en todas partes se guardan al alto comercio honrado y serio. [Espero] usted hará entender a algunos agentes administrativos de Nahuel Huapi y otros boquetes de la cordillera, que es una obra poco patriótica y contraria a los intereses bien entendidos de la República Argentina, el poner estorbos y ejecutar actos de hostilidad contra la casa Hube \& Achelis", citado por Méndez y Muñoz (2013, pp. 158-159).

${ }^{20}$ El decreto dice: "Vista la presentación de los señores Hube \& Achelis pobladores de la parte occidental del Río Negro, pidiendo para esa región las mismas libertades de que, para canon de aduanas, gozan los territorios limítrofes del Chubut y Neuquén y atento a lo informado por la inspección de aduanas y teniendo en cuenta que aparte de que por razones de conveniencia pública, para el fomento de esas localidades, puesto que en nada se perjudica el comercio general, desde que por la distancia y condiciones que la rodean no pueden importarse mercaderías de contrabando en los territorios de la Pampa Central o de la provincia de Buenos Aires que disponen de administración de renta", citado por Bandieri y Blanco (2001, pp. 389-390) y Maggiori (2016, p. 51). 
nación en Buenos Aires. Esta facilitó la importación de bienes de capital para mecanizar sus faenas de procesamiento de lana, trigos y maderas, junto a otros de uso cotidiano, que eran vendidos en sus tiendas comerciales (preferencialmente a sus empleados y trabajadores).

Las buenas relaciones con el gobierno de Roca no acabaron ahí, ya que se sumó la compra de tierras a la familia Uriburu en Neuquén (emparentada matrimonialmente con una hija de Roca), que ascendieron a 260623 hectáreas. El traspaso se produjo no a través de un acuerdo monetario, sino por la creación de un directorio de la Hube y Achelis en Argentina, donde los vendedores pasaron a ocupar puestos directivos (Bandieri y Blanco, 2009, pp. 178-179; Blanco, 2012, p. 119).

La ampliación de las redes políticas de la empresa, y las consecuentes exigencias que deparaba para sus administradores, probablemente impulsaron su transformación en sociedad anónima y la búsqueda de nuevos socios políticos en el puerto chileno de Valparaíso. A inicios de 1904 se acordó con el grupo Subercaseaux -familia que controlaba el Banco Mobiliario, el llamado banco del salitre-, la creación de una nueva sociedad anónima, denominada Sociedad Agrícola y Ganadera Chile-Argentina. Ella se establecería sobre los pasivos y activos de la Hube y Achelis (cerca de 1700000 pesos chilenos o 26500 libras esterlinas), sus acciones saldrían a la bolsa y se entregaría el cargo de director-gerente a Federico Hube -quedando Achelis en la posición de accionista minoritario (Compañía Comercial Ganadera Chile y Argentina, 1904, pp. 3-5).

$\mathrm{Al}$ interior del nuevo directorio descollaban las figuras de Carlos Concha Subercaseaux, antiguo embajador plenipotenciario de Chile en Argentina y Ramón Subercaseaux Vicuña, embajador de Chile en Alemania. Su entrada en la empresa se debió a las expectativas económicas que generaba la exportación lanar y a los positivos informes comerciales de la Hube y Achelis. ${ }^{21}$ No obstante, para la empresa eran las relaciones diplomáticas de la familia el factor perseguido. Eso queda comprobado al constatar que nadie del directorio ingresó aportes de capital a la empresa, pudiendo afirmarse que el capital aportado por el grupo Subercaseaux fue político, y no pecuniario. Un capital político que era altamente valioso si se deseaba mantener la posición de la empresa frente a la aparición de nuevos competidores en la región.

${ }^{21}$ En 1904 el balance de la Hube y Achelis informó que contaba con catorce sedes o casas comerciales en los territorios de Río Negro, Chubut y Neuquén, además de cinco en Chile (Casa Pangue, Frutillar, Nueva Braunau, Puerto Varas y Puerto Montt). Además de 100000 ovejas, varios cientos de cabezas caballares y de vacunos y que, únicamente en existencias de mercadería, tenía 360000 pesos chilenos (Méndez, 2009, p. 31, y 2010, p. 173; Weil, 2006, p. 79). 
UNA EMPRESA PRIVADA EN BÚSQUEDA DE LA SOBERANÍA TERRITORIAL

Hacia fines de 1904 los gobiernos argentino y chileno dispusieron la concesión de todos los terrenos adquiridos por el laudo arbitral, lo que colocó a disposición de la especulación privada gran parte de los valles andinos entre los paralelos 40 y 45 (Martinic, 2005, p. 119; Navarro, 2010; Salazar, 1999, p. 38). En concordancia con esta política, en Chile se gestaron poco más de 60 sociedades anónimas pensadas para aprovechar las ventajas que daban las concesiones de tierras, viéndose beneficiadas con 4700000 hectáreas de tierras públicas en las regiones andinas de Llanquihue y Aysén (Almonacid, 2005, p. 155; Vial, 1981-2001, vol. II, p. 401). Aquella política estatal se comprendía por el crecimiento de las ciudades salitreras del norte de Chile y la necesidad de impulsar un mercado interno de abastecimiento de productos cárnicos, ya que el hato bovino y ovino de la zona central del país era insuficiente (Pinto y Ortega, 1990, pp. VI, VIII y 78). Esta política de incentivos iba asociada a una reglamentación más estricta en las aduanas con Argentina (llamadas resguardos de cordillera). Tanto la aparición de competidores comerciales como el endurecimiento de la reglamentación aduanera fueron vistos como una contingencia negativa por la Hube y Achelis (en vías de transformarse en la Sociedad Ganadera y Comercial Chile-Argentina), gestándose acciones de presión específicas para detener o retrasar tales cambios.

Cabe recordar que en 1904 la Hube y Achelis había logrado que el gobierno argentino dictara una ley que posibilitó que no pagara aduana al ingresar productos por el paso Pérez Rosales, e intentó lograr lo mismo con los bienes importados desde Argentina (lana, principalmente), ahora en gestión con el gobierno chileno. De tal manera, solicitó formalmente al superintendente de Aduanas, el liberal Francisco Valdés Vergara, que recomendara al Congreso que se reconociera al paso Pérez Rosales como puerto chileno y, además, se le erigiera en puerto mayor -o sea un punto donde se podía importar y exportar productos, a diferencia de los puertos menores donde únicamente se podían registrar productos en tránsito-. Aducía la Hube y Achelis, para justificar su solicitud, que, gracias a su empresa, Chile ahora podía beneficiarse económicamente de los valles perdidos en el laudo arbitral. ${ }^{22}$ Es interesante ver cómo el argumento de

${ }^{22}$ El informe del superintendente leído en la Cámara de Diputados decía: "Señor Ministro: Es notorio que en la región austral una extensa zona de la República Argentina, adecuada en parte para la crianza de ganado i en parte para la crianza de ganado i en parte para el cultivo de cereales, carece de comunicación con el Atlántico i tiene que exportar sus productos e internar sus artículos de consumo por los puertos de Chile. [...] En este caso se encuentran los campos argentinos que hoy hacen su comercio exterior por Puerto Montt, sirviéndose para ello de los elementos de transporte que los señores Hube i Achelis han establecido en los lagos Llanquihue, Todos [los] 
la empresa era la inversión de los ataques que parte de la prensa argentina refería contra la Hube y Achelis o sus homólogas, a las que consideraban parte de un plan gestado por el gobierno chileno para ejecutar una soberanía de facto en los valles andinos. ${ }^{23}$

Este informe fue presentado a su discusión en la Cámara de Diputados, en enero de 1905, pero fue retrasado por el ministro de Hacienda, el radical Ernesto Hübner, que llamó a revisar si la disposición no afectaría la recaudación por aduana. Tras su petición, se dispuso el envío del proyecto a la Comisión de Hacienda, donde permaneció casi un año. ${ }^{24}$ En Valparaíso, contemporáneo a estos sucesos, la gestación de sociedades ganaderas, constituidas únicamente para captar las concesiones de tierras públicas, había provocado una crisis especulativa. ${ }^{25}$

Gonzalo Vial (1981-2001, vol. II, p. 404), al narrar esta crisis, refirió que de las 50 sociedades ganaderas constituidas previamente, únicamente diez le sobrevivieron y, de ellas, cuatro cotizaban sus acciones a $37 \%$ por debajo de su precio nominal de referencia. En este agitado año de 1905, la Chile-Argentina mostró la solidez ganada en los años previos, tanto en el plano económico como político. En el mes de enero de 1905 salieron a bolsa sus acciones, alcanzando un precio por acción de 146 pesos -para una acción de cinco libras o 32 pesos chilenos-. En febrero habían descendido

\footnotetext{
Santos i Nahuelhuapi. [...] Para dar facilidades a este comercio de tránsito por territorio chileno se ha presentado el proyecto de ley que abre un puerto mayor de cordillera en el boquete de Pérez Rosales. Dicho proyecto tuvo origen en una solicitud de los señores Hube i Achelis, quienes pedían se autorizase el libre tránsito por aquel boquete a fin de no pagar dobles derechos de internación en la Aduana chilena de Puerto Montt y en la Argentina de la frontera por las mercaderías extranjeras destinadas al consumo de los pobladores que residen al oriente de la cordillera. [...] La Superintendencia considera que hay ventajas positivas para Chile en atraer al Pacífico el comercio de aquellos territorios argentinos y, en consecuencia, informa en sentido favorable la solicitud de los señores Hube i Achelis." Cámara de Diputados. Sesión 78a. extraordinaria, 19 de enero de 1905, pp. 1690-1691.

${ }_{23}$ El antiguo perito de la Comisión de Límites, Francisco Moreno, fue uno de los más fervientes difusores de la tesis del complot gubernamental chileno para hacerse con los valles cordilleranos de Argentina: "Inmediatamente de dictado el fallo por el árbitro, Chile se apresuró a fomentar la formación de sociedades agrícolas ganaderas que penetrasen por los valles transversales de la cordillera y poblaran sus partes orientales, las únicas de posible rendimiento. Así se formó la compañía de río Cisnes y la del Aysén, hoy florecientes y que se van extendiendo a los campos argentinos." Véase Francisco Moreno, Carta de Francisco Moreno al Interventor de la Dirección de Tierras y Colonias (12 de mayo de 1917). La Unión, p. s. n. Colección Moreno, caja 7, documento 65 [Recorte de prensa], Museo de la Patagonia, Bariloche, Argentina.

${ }^{24}$ Véase Diario de Sesiones, Cámara de Diputados, Sesión 84a. extraordinaria, 24 de enero de 1905, pp. 1824-1825.

25 "Hay fiebres tifoideas, fiebres palúdicas, fiebres amorosas, fiebres intermitentes, pero á pesar de ser fiebres no alcanzan a subir de punto como la que se ha desarrollado en la calle de Prat con el nombre de fiebre bursátil-ganadera. Ya no se habla sino de sociedades en gestación; el ganado es lo del día y como con el ganado se gana, no hay más que papeletas de terneros, vacas, bueyes y hasta de micos que corren de mano en mano." Véase La fiebre bursátil (1905, p. 26). Para una visión global del fenómeno, véase Subercaseaux (1922, p. 121).
} 
a 107 pesos y continuó su descenso hasta mayo, cuando se cotizaron en 73 pesos (todavía muy por encima de su valor real). En junio las acciones vieron sustantivas alzas (81.50 pesos) y para julio y agosto habían llegado a cifras similares a las originales (132 y 139 pesos, respectivamente), dando cuenta que había superado sin mayores inconvenientes las fluctuaciones de mercado que destruyeron a otras sociedades (Precio corriente, 1905, pp. 144, 206, 382, 445, 532 y 592).

El resultado del quiebre de las sociedades ganaderas fue la concentración de las concesiones estatales en las sociedades anónimas que perduraron, procediendo la Chile-Argentina como una organización presta a fusionarse, amén de captar la mayor cantidad de terrenos en Llanquihue, Río Negro, Neuquén y Chubut (Blanco, 2012).

En Chile actuó de mediador el antiguo diputado conservador por Llanquihue, Osorno y Carelmapu, Julio Subercaseaux Browne, que además ejercía como gerente del Banco Mobiliario de la familia Subercaseaux. Él pudo comprar las concesiones Rodríguez Bravo y Tornero, situadas en la ribera norte del río Maullín, desembocadura del lago Llanquihue. Una vez adquiridas, con la ayuda de la sociedad Valle Central, se dispuso la transferencia de las concesiones a la Chile-Argentina ${ }^{26}$ En Neuquén, el director Carlos Concha Subercaseaux y José Ramila compraron dos concesiones equivalentes a 159114 hectáreas en posesión del Banco de Crédito Italiano de Buenos Aires. Inmediatamente ambos crearon en Chile la Sociedad Agrícola del Neuquén, que en 1905 se fusionó con la Chile-Argentina a cambio de participación accionaria. Eso hizo que la Chile-Argentina, únicamente en Neuquén, contara con 420000 hectáreas, adquiridas o concesionadas (Blanco, 2012, pp. 119-120).

El acceso a estas concesiones en Argentina y Chile hizo que la empresa dispusiera de una franja transversal de terrenos, desde el río Limay hasta el océano Pacífico (véase mapa 1). En definitiva, únicamente le restaba el reconocimiento como puerto mayor al paso Pérez Rosales, para consolidar un corredor económico que podría trasladar los productos lanares desde

\footnotetext{
${ }^{26}$ Los terrenos concesionados superaban las 230000 hectáreas, muchas de ellas ubicadas en los terrenos de pastaje más fértiles de la provincia de Llanquihue. Sobre la concesión original y su extensión, véase Anexo Documentos mandados publicar a petición del señor Puga Borne, Diario de Sesiones, Cámara de Diputados, Sesión 54a. extraordinaria, 29 de diciembre de 1906, p. 1433. Subercaseaux Browne (1976) recordaría en sus memorias los réditos económicos que le significó su acción en favor de Hube: "Como gerente del Banco, y rodeado de gente sensata como don Francisco Javier Riesco, que iba a diario a vaticinar las peores consecuencias, no metí al Banco en ningún negocio, pero personalmente no pude resistir a tan tentadora ocasión. Recuerdo un negocio que hice con Arturo López Pérez, Carlos Edwards, Juan Enrique y Juan Magalhaes en el cual gané doscientos mil pesos sobre la Compañía de Salitre de Antofagasta, otra del Valle Central, en compañía de Alejandro Valdés Riesco, Hube y Francisco Celis, en que gané otro tanto" (p. 280).
} 


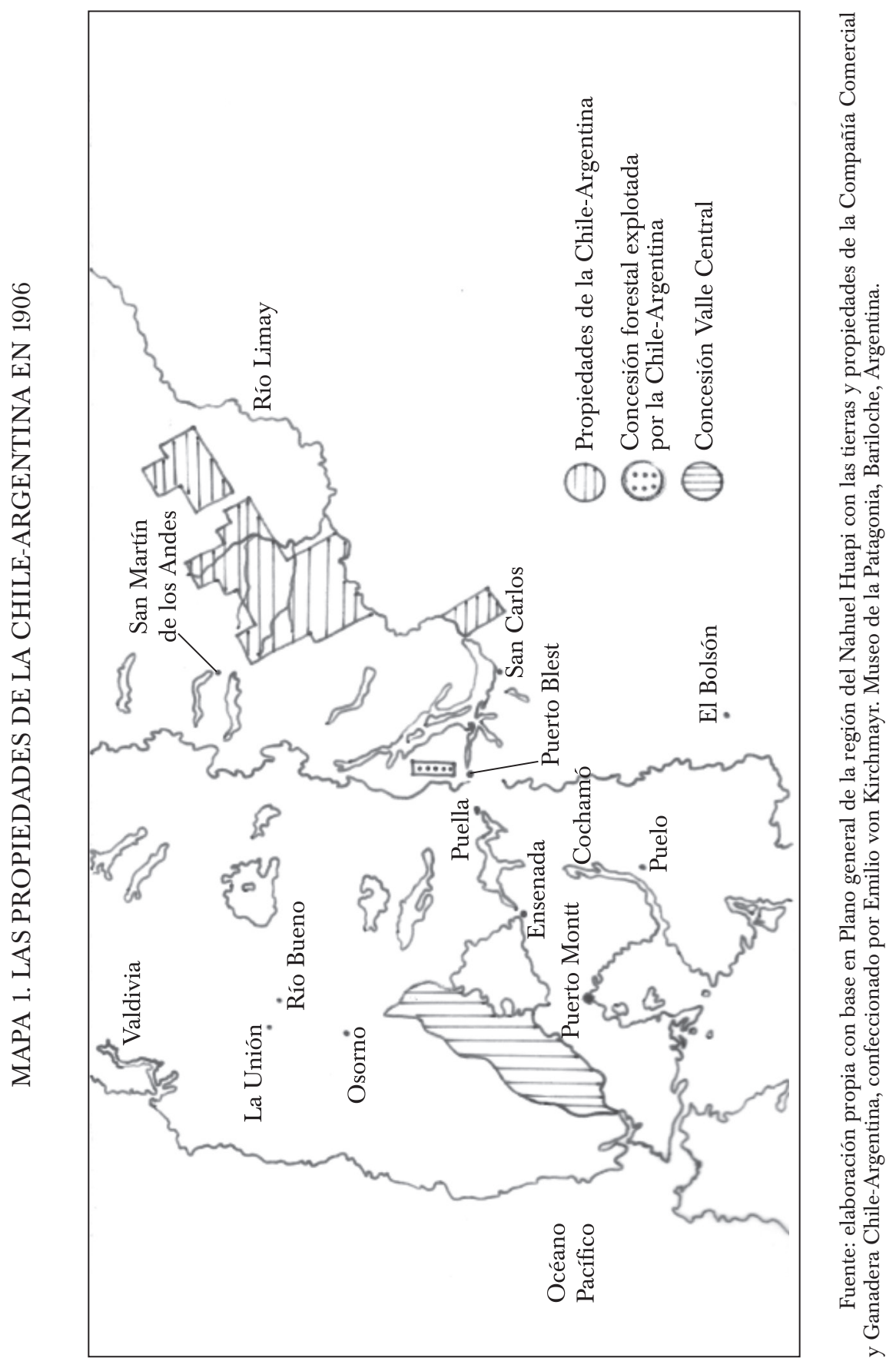


la pampa argentina al océano Pacífico, con absoluta prescindencia de las barreras gubernamentales.

Luego de casi un año, el día 29 de diciembre de 1905 la Comisión de Hacienda de la Cámara de Diputados emanó un halagüeño informe sobre la proposición de la Hube y Achelis, y las implicancias que tendría para Chile si atraía los productos de la Patagonia argentina, además de agregar una recomendación al informe original: no permitir que otros resguardos de cordillera, como el de Cochamó, pudieran pasar a puertos mayores. ${ }^{27}$ Tal recomendación, probablemente producto de presiones por parte de la Chile-Argentina, hacía inviable la colocación de las pocas sociedades ganaderas que habían sobrevivido la crisis especulativa -ya que muchas de ellas pensaban establecerse en ambas franjas de la cordillera, disponiendo de un paso cordillerano para importar y exportar, a la manera de la Chile-Argentina.

Frente a algunas preguntas menores de los congresistas, dos integrantes de la comisión (el conservador Darío Urzúa y el liberal-democrático José Agustín Verdejo) defendieron la propuesta, destacando la labor de la Chile-Argentina como una importante empresa y que este proyecto venía a facilitar su comercio e impedir la doble tributación -argumento inexacto, ya que gracias a las modificaciones aduaneras argentinas de 1904 se había eliminado tal posibilidad-.$^{28}$ La cerrada defensa de los diputados llevó a que fuera votado el informe como proyecto, obteniendo su aprobación, sin debates ni votación. ${ }^{29}$

Por consiguiente, este proyecto pasó a la Comisión de Hacienda del Senado, que en menos de un mes emanó un informe confirmando las conclusiones del anterior, elevando al paso Pérez Rosales como puerto mayor chileno, siendo el único entre la Araucanía y Magallanes. ${ }^{30}$ Para finalizar, la empresa se acogió a la ley 1.187 del 26 de enero de 1899, que le permitió ingresar sus productos a Chile sin pagar aduana y que al momento de exportar la lana a Alemania, ella pasara como bien chileno (exentos de pago por exportación) (Actas oficiales, 1899, p. 3). Cerrándose así un circuito productivo que era virtualmente independiente de los Estados nacionales.

${ }^{27}$ El Informe de la Comisión desdeñaba directamente algunas imputaciones hacia la empresa y sus intenciones: "no pueden ser un obstáculo para elevar la categoría de este puerto ante la conveniencia, por todos reconocida, de traer al Pacífico el comercio de los territorios argentinos colindantes con aquella parte de la región austral del país”. Diario de Sesiones, Cámara de Diputados, Sesión 39a. extraordinaria, 29 de diciembre de 1905, pp. 971-972.

${ }^{28}$ Diario de Sesiones, Cámara de Diputados, Sesión 39a. extraordinaria, 29 de diciembre de 1905, p. 973.

${ }_{29}$ Diario de Sesiones, Cámara de Diputados, Sesión 44a. extraordinaria, 11 de enero de 1906, p. 1154.

${ }^{30}$ Diario de Sesiones, Cámara de Senadores, Sesión 55a. extraordinaria, 26 de enero de 1906, p. 1414. 
La aprobación de este proyecto puede considerarse como el punto culminante de la antigua Hube y Achelis en Chile (y por eso marca el fin de este trabajo), ya que en los años posteriores las relaciones del directorio con el mundo político se enfriaron. El Banco Mobiliario, de la familia Subercaseaux, quebró en 1907 incitando la venta de sus acciones a inversores alemanes. La desaparición de la mediación política de los Subercaseaux allanó el camino para que, desde 1908, se imputara la forma de adquisición de las concesiones por la empresa, frenándose la entrega en derecho de ellas. Tales factores llevaron a los inversores alemanes a olvidar el mercado chileno y recluirse en Argentina, transformándose en la principal fuerza económica de la naciente ciudad de San Carlos (Méndez, 2010; Vallmitjana, s. f.). Esta nueva etapa conlleva factores que la estructura acotada de este artículo no permiten profundizar, a riesgo de deformar nuestro objetivo original.

\section{CONCLUSIÓN}

La pregunta original de este trabajo partía de la tentativa hipótesis de Vidal, que adujo que el principal factor que condiciona las relaciones políticas de los empresarios son sus relaciones sociales y familiares con actores gubernamentales, la que quisimos proponer en términos diferentes: ¿̇es posible que empresarios sin relaciones familiares ni sociales con actores gubernamentales puedan beneficiarse de prerrogativas estatales? Al término de este escrito la respuesta es afirmativa, pero nos obliga a proponer una explicación tentativa.

A diferencia de la historiografía chilena, en Argentina ya se habían encontrado investigaciones que estudiaron cómo empresas extranjeras obtuvieron un trato preferencial por parte del Estado, mas tales trabajos han estado abocados sólo al caso de los ferrocarriles (Justo, 2010; Regalsky, 1996; Wadell, 2010). Estos trabajos, habitualmente, presentan a los empresarios como grupos de presión por su calidad de extranjeros, sin profundizar en lo que significa aquello y la importancia que tuvo el rubro o territorio donde se situaron.

En nuestro caso de estudio presentamos a una empresa de capitales extranjeros, con giro comercial, de un valor significativo en sus sociedades de asiento pero insignificante a escala nacional (tanto en Argentina como en Chile) y que logró que los Estados eliminaran las aduanas en sus espacios de intercambio - pago aduanero que era, finalmente, el único aporte directo de la empresa a los erarios estatales, sin considerar la generación de empleo-. Para comprender el porqué de aquello, creemos que se debió a que supo conjugar los tres factores que tuvo a su disposición: primero, 
los lenguajes dicotómicos y belicistas de la política nacional; segundo, su posición dentro de un espacio geopolíticamente disputado y, tercero, el manejo de las redes políticas obtenidas gracias a los dos puntos anteriores.

La Hube y Achelis aprovechó el discurso político de la época para crearse redes locales y luego amplió su esfera para apropiarse de conceptos propios de la época entre los parlamentos del Cono Sur americano (religión, nacionalismo económico y progreso), al punto de presentarse como la encarnación de ellos -en un grado superior, inclusive, a los cuerpos gubernamentales creados por los Estados en tales territorios-. Su asentamiento en una región disputada, y su calidad de extranjeros, hizo que pudiera actuar como comodín discursivo que, ajustándose a los debates inmediatos de los grupos políticos nacionales, pudo obtener concesiones y prerrogativas que impactaron en un largo plazo a las regiones fronterizas.

Este trabajo, dentro de sus acotadas expectativas, nos permite avanzar en el estudio histórico de cómo durante el siglo XX se produjo una privatización de los imaginarios nacionales y cómo aquello, a su vez, construyó sociedad y sentido común dentro de los países del Cono Sur americano, particularmente en las regiones alejadas de las capitales nacionales. Dando pie para estudios posteriores que vean a los empresarios como constructores de política pública y, por lo mismo, de discurso nacional que se plasma en representaciones culturales que funden el ideario empresarial con la retórica nacionalista. Consideramos que esta podría ser una riquísima veta para integrar la historia de la empresa dentro del debate de la historia política y social.

\section{LISTA DE REFERENCIAS}

Actas oficiales. Libre tránsito de las lanas, cueros, crin i pieles (1899). Boletín de la Sociedad de Fomento Fabril, 16(1), 3.

Almonacid, F. (2005). La agricultura del sur de Chile (1910-1960) y la conformación del mercado nacional (Tesis doctoral inédita). Universidad Complutense de Madrid, España.

Álvarez, R. (2015). Gremios empresariales, política y neoliberalismo. Los casos de Chile y Perú (1986-2010). Santiago de Chile: Lom Ediciones.

BANDIERI, S. y BlAnCO, G. (2001). Invirtiendo en tierras y ganados: capitales chilenos en la frontera norpatagónica. En S. BANDIERI (coord.), Cruzando la cordillera .. La frontera argentino-chilena como espacio social (pp. 375-396). Argentina: Universidad del Comahue.

Bandieri, S. y Blanco, G. (2009). Política de tierras en los territorios nacionales: entre la norma y la práctica. En G. Blanco y G. BANZATO (comps.), La cuestión de la tierra pública en Argentina (pp. 163-199). Córdoba: Prohistoria Ediciones. 
BAuer, A. (1990). Industry and the missing bourgeoisie: Consumption and development in Chile, 1850-1950. The Hispanic American Historical Review, 70(2), 227-253. Recuperado de http://www.jstor.org/stable/2516479

BÉJAR, M. (2005). El régimen fraudulento. La política en la Provincia de Buenos Aires, 19301943. Buenos Aires: Siglo XXI Editores.

BERnEDo, P. (1993). Las iglesias alemanas frente al problema de la emigración masiva, 1816-1914. Historia, 27, 69-87.

BLANCO, G. (2012). Las sociedades anónimas cruzan los Andes: los inversores chilenos en Neuquén al comenzar el siglo Xx. América Latina en la Historia Económica, 19(2), 107-130. DOI: 10.18232/alhe.v19i2.519

Blancpain, J. P. (1970). La tradición campesina alemana en Chile. Santiago de Chile: Liga Chileno-Alemana.

Brennan, J. y Rougier, M. (2013). Perón y la burguesía argentina. El proyecto de un capitalismo nacional y sus límites (1946-1976). Buenos Aires: Lenguaje Claro Editora.

Camus, P. (1997). Ordenamiento territorial y ferrocarril del sur en Osorno y Llanquihue, 1860-1960. Revista de Geografía Norte Grande, 24, 165-173.

Carrasco, R. (2015). La construcción del ferrocarril Osorno-Puerto Montt (18951911). Revista Llanquihue Historia, 1, 57-99.

CARreño, L. (2008). La Sociedad Agrícola y Ganadera de Osorno (SAGO) y su aporte al desarrollo de la comunidad regional. Espacio Regional, 5(1), 35-48.

Carrière, J. (1981). Landowners and politics in Chile. A study of the Sociedad Nacional de Agricultura 1932-1970. Ámsterdam: Centro de Estudios y Documentación Latinoamericanos.

CAVIEREs, E. (2002). Crecimiento y modernización: la experiencia chilena de los sectores dirigentes, siglos XVIII al XX. En G. LIZAMA (coord.), Modernidad y modernización en América Latina. México y Chile, siglos XVIII al XX (pp. 137-167). Santiago de Chile: Universidad de Guadalajara/Dibam.

Compañía Comercial Ganadera Chile y Argentina (1904). Estatutos de la Compañia Comercial Ganadera Chile y Argentina. Santiago de Chile: Imprenta, Litografía y Encuadernación Barcelona.

Correa, S. (1981). El Partido Conservador ante las leyes laicas 1881-1884. En R. Krebs et al., Catolicismo y laicismo (pp. 76-118). Santiago de Chile: Editorial Nueva Universidad de la Pontificia Universidad de Chile.

Correa, S. (2011). Con las riendas del poder. La derecha chilena en el siglo XX. Santiago de Chile: Sudamericana/DeBolsillo.

Corvalán, L. (2002). El proyecto conservador. En M. LOYOla y S. Grez (comps.), Los proyectos nacionales en el pensamiento político y social chileno en el siglo XIX (pp. 55-60). Santiago de Chile: Ediciones Universidad Católica Silva Henríquez.

Couyoumdjian, R. (1986). Chile y Gran Bretaña durante la primera guerra mundial y la postguerra, 1914-1921. Santiago de Chile: Editorial Andrés Bello/Editorial Universidad Católica de Chile. 
DÁvila, C. (2015). Familias empresarias y política. Dinastías presidenciales en Colombia (1850-2010). En P. Fernández y A. Lluch (eds.), Familias empresarias y grandes empresas familiares en América Latina y España (pp. 263-292). Bilbao: Fundación BBVA.

Donoso, R. (1936). El Dr. Hans Steffen. Anales de la Universidad de Chile, 22-23, 5-18.

El comercio esterior de Chile en 1901 i 1902 según la reciente Memoria de la Superintendencia de Aduanas (1903). Boletín de la Sociedad de Fomento Fabril, 20(8), 286 y 293.

ERNESTO TORQUiST Y COMPAÑÍA LIMITADA (1919). The economic development of the Argentine Republic in the last fifty years. Buenos Aires: s. e.

FÁbregas, P. (2014). Puerto Montt. Capital del comercio de la Patagonia sur austral. Identidad cultural y liderazgo en el antiguo Melipulli (1771 a 2013). Valdivia: Kultrún.

Fernández, P. y LLUCH, A. (eds.) (2015). Familias empresarias y grandes empresas familiares en América Latina y España. Bilbao: Fundación BBVA.

FiORI, J. y VERAS, G. DE (2002). 1902. El protagonismo de los colonos galeses en la frontera argentino-chilena. Argentina: Municipalidad de Trevelin.

Gazmuri, C. (1980). Testimonios de una crisis. Chile: 1900-1925. Santiago de Chile: Editorial Universitaria.

GÓNGORA, M. (2003). Ensayo histórico sobre la noción de Estado en Chile en los siglos XIX y XX [1981]. Santiago de Chile: Editorial Universitaria.

Harris, G. (1998). Privilegios exclusivos y mentalidad empresarial en la temprana industrialización chilena 1840-1879. Mapocho, 44, 105-122.

Holdich, T. H. (1904). The countries of the King's award. Londres: Hurst and Blackett Lted.

HORA, R. (2009). Los estancieros contra el Estado. La liga agraria y la formación del ruralismo político en Argentina. Buenos Aires: Siglo XXI Editores.

HorA, R. (2015). Los terratenientes de la pampa argentina. Una historia social y política. Buenos Aires: Siglo XXI Editores.

Jocelyn-Holt, A. (1997). El peso de la noche. Nuestra frágil fortaleza histórica. Santiago de Chile: Editorial Planeta/Ariel.

Justo, M. (2010). La política ferroviaria del primer gobierno radical 1916-1922. $H$ Industria, 7(4), 2-37.

Krebs, R. (2001). Carl Adwandter y la colonia alemana en Valdivia. En C. AdwANDTER, Desde Hamburgo a Corral: diario de viaje de Carl Adwandter a bordo del velero Hermann. Santiago de Chile: Pehuén Editores/Universidad Austral de Chile.

La fiebre bursátil (1905). Sucesos, 128.

Lacoste, P. (2003). La imagen del otro en las relaciones de la Argentina y Chile (1534-2000). Santiago de Chile: Fondo de Cultura Económica.

Maggiori, E. (2016). Problemas limítrofes a comienzos del siglo XX, que casi provocan una guerra. Trelew: Remitente Patagonia.

Martinic, M. (2005). De la Trapananda al Aysén. Santiago de Chile: Pehuén Editores. 
Matossian, B. (2012). Modelos de desarrollo, poblamiento y frontera: el caso del Parque Nacional Nahuel Huapi. Estudios Sociales Contemporáneos, 5-6, 67-84. Recuperado de http://bdigital.uncu.edu.ar/4970

Matus, M. (2012). Crecimiento sin desarrollo. Precios y salarios reales durante el ciclo salitrero en Chile (1880-1930). Santiago de Chile: Editorial Universitaria.

MAzzeI, L. (1998). Expansión de gestiones empresariales desde la minería del norte a la del carbón, Chile, siglo XIX. Boletín de Historia y Geografía, 14, 249-265.

Méndez, L. (2009). "El león de la cordillera". Primo Capraro y el desempeño empresario en la región del nahuel Huapi, 1902-1932. Boletín Americanista, 59, 29-46.

Méndez, L. (2010). Estado, frontera y turismo. Historia de San Carlos de Bariloche. Buenos Aires: Prometeo libros.

Méndez, L. y MuÑoz, J. (2013). Alianzas sectoriales en clave regional. La Norpatagonia argentino-chilena entre 1895 y 1920. En M. A. NicOletTi y P. NúÑEZ (eds.), Araucaní-Norpatagonia: la territorialidad en debate (pp. 152-167). Bariloche: Universidad Nacional de Río Negro.

Merrett, D. T. y Ville, S. (2015). Accounting for nonconvergence in global wool marketing before 1939. Business History Review, 89(2), 229-253. DOI: 10.1017/ S0007680515000641

Moreno, F. (1898). La guerra posible entre Chile y la Argentina. Para el comandante Manuel Prado. Mundo Naval Ilustrado, 36, 460.

Moulian, T. y Torres, I. (2011). Discusiones entre honorables. Triunfos, fracasos y alianzas electorales de la derecha en Chile, 1938-2010. Santiago de Chile: Editorial Arcis/ Akhilleus.

Muñoz, M. A. (2009). El Partido Conservador: 1878-1906. Una mirada retrospectiva: la Convención de 1947. Anuario Historia de la Iglesia en Chile, 27, 29-52.

Navarro, P. (2010). La conquista de la Patagonia y el reparto de tierras. En Archivos DEL SuR, Historia de las familias Mapuche Lof Paichil Antriao y Lof Quintriqueo. Mapuche de la margen norte del lago Nahuel Huapi. Córdoba: Ferreyra Editores.

NAZER, R. (2000). El surgimiento de una nueva elite empresarial en Chile: 1830-80. En F. BONELli y M. R. StABILI (coords.), Minoranze e culture imprenditoriale Cile e Italia, secoli 19-20 (pp. 59-84). Roma: Università degli Studio di Roma tre.

Onelli, C. (2007). Trepando los Andes. Un naturalista en la Patagonia argentina (1903). Buenos Aires: Ediciones Continente-Pax.

Ortega, L. (1984). Los empresarios, la política y los orígenes de la guerra del Pacífico. Santiago de Chile: Facultad Latinoamericana de Ciencias Sociales.

Ortega, L. (1999). Business history in Chile 1850-1945. En C. Dávila y R. Miller (eds.), Business history in Latin America: The experience of seven countries (pp. 60-82). Liverpool: Liverpool University Press.

Overlack, P. (1998). "Bless the queen and curse the colonial office": Australasian reaction to German consolidation in the Pacific, 1871-1899. The Journal of Pacific History, 33(2), 133-152. Recuperado de http://www.jstor.org/stable/25169384 
PinTo, J. (2002). La economía: mercados, empresarios y trabajadores (t. III). En G. SALAZAR y J. Pinto, Historia contemporánea de Chile. Santiago de Chile: Lom Ediciones. Pinto, J. y ORTEga, L. (1990). Expansión minera y desarrollo industrial: un caso de crecimiento asociado (Chile 1850-1914). Santiago de Chile: Editorial de la Universidad de Santiago de Chile.

Precio corriente de las acciones y bonos (1905). Boletín de la Sociedad de Fomento Fabril, 22(2-3-6-7-8-9), 144, 206, 382, 445, 532 у 592.

Rabelli \& Sille Editores (1921). Die Familie Achelis in Bremen 1579-1921. Leipzig: Rabelli \& Sille.

RAMÓn, A. DE (2003). Biografías de chilenos (4 vols.). Santiago de Chile: Universidad Católica de Chile.

Regalsky, A. (1996). Las compañías francesas de ferrocarriles y su repercusión en el desarrollo regional de Santa Fe y Buenos Aires, 1880-1930. En C. MARICHAL (ed.), Las inversiones extranjeras en América Latina, 1850-1930 (pp. 193-213). México: Fondo de Cultura Económica.

Rinke, S. (2014). Germany and Brazil, 1870-1945: A relationship between spaces. História, Ciências, Saúde-Manguinhos, 27(1), 1-16. DOI: 10.1590/S0104-59702014005000007

Ross, B. y KARCHER, S. (2012). La política de las empresas en Latinoamérica: investigando sus estructuras, preferencias e influencia. Apuntes, 39(70), 7-28. DOI: $10.21678 / 0252-1865$

Rozas, R. (1899). Manifiesto en que el Senador por Llanquihue don Ramón Ricardo Rozas da cuenta a los electores de esa provincia como ha desempeñado el mandato que se le confirió en el periodo legislativo de 1894 a 1900. Santiago de Chile: s. d.

Sabato, H. (1983). Wool trade and Commercial Networks in Buenos Aires, 1840s to 1880s. Journal of Latin American Studies, 15(1), 49-81. Recuperado de http://www. jstor.org/stable/155923

SAlazar, G. (1999). Tomo I: Estado, legitimidad, ciudadanía. En G. SAlazar y J. PINTO, Historia contemporánea de Chile. Santiago de Chile: Lom Ediciones.

SAlazAR, G. (2015). La enervante levedad histórica de la clase política civil (Chile, 19001973). Santiago de Chile: Debate.

SimOnassi, S. (2015). Los industriales ante el frondicismo: corporaciones, capital extranjero y desarrollo industrial. Gran Rosario, 1958-1962. Anuario Centro de Estudios Económicos de la Empresa y el Desarrollo, 7, 103-144.

Steffen, H. (1910). Der Anteil der Deutschen an der geographischen und geologischen Erforschung der Republik Chile während der ersten Jahrhunderts ihres Bestehens. En Deutschen Wissenschaftlichen Vereins, Deutsche Arbeit in Chile (t. 1, pp. 188-245). Santiago de Chile: Imprenta Universitaria.

Steffen, H. (2010). Viajes de exploración y estudio a la Patagonia occidental 1892-1902 (t. II). Santiago de Chile: Dibam.

Subercaseaux Browne, J. (1976). Reminiscencias. Santiago de Chile: Nascimento.

Subercaseaux, G. (1922). Monetary and banking policy in Chile. Londres: Humphrey Milford. 
Vallmitjana, R. (s. f). Sociedad Comercial y Ganadera Chile-Argentina 1900-1916. Bariloche: Museo de la Patagonia.

VIAL, G. (1981-2001). Historia de Chile (1891-1973) (5 vols.). Santiago de Chile: Editorial Santillana.

VIAL, G. (2003). Un libro estimulante. En M. GÓNGORA [1981], Ensayo histórico sobre la noción de Estado en Chile en los siglos XIX y XX (pp. 341-347). Santiago de Chile: Editorial Universitaria.

VIDAL, J. (2015). El Estado y el impacto de las políticas económicas en la evolución histórica de las empresas familiares en España y América Latina. En P. FERnÁndez y A. LLUCH (eds.), Familias empresarias y grandes empresas familiares en América Latina y España (pp. 95-124). Bilbao: Fundación BBVA.

Villalobos, S. (1984). Sugerencias para un enfoque del siglo XIX. Colección Estudios Cieplan, 12, 9-36.

Villalobos, S. (1987). Origen y ascenso de la burguesía chilena. Santiago de Chile: Editorial Universitaria.

WADELL, J. (2010). El mecanismo de control de capital de las empresas ferroviarias a partir de la ley Mitre. H-Industria, 7(4), 1-23.

WEIL, J. (2006). Frutillar: pasado y presente. Valdivia: Ilustre Municipalidad de Frutillar/ Editorial Universidad de Los Lagos. 